\title{
ANGKA KEJADIAN LUTS YANG DISEBABKAN OLEH BPH DI RSUP PROF. DR. DR. R. D. KANDOU MANADO PERIODE 2009-2013
}

\author{
${ }^{1}$ Gloria Sampekalo \\ ${ }^{2}$ Richard A. Monoarfa \\ ${ }^{2}$ Billy Salem
}

${ }^{1}$ Kandidat Skripsi Fakultas Kedokteran Universitas Sam Ratulangi Manado
${ }^{2}$ Bagian Ilmu Bedah RSUP Prof. Dr. R. D. Kandou Manado
Email: glopink_archuleta@yahoo.co.id

\begin{abstract}
Lower urinary tract symptoms (LUTS) often occur among old-aged population. One of the causes of LUTS in aged males is benign prostatic hyperplasia (BPH). Males with severe LUTS will experience decreased libido, difficulty in enducing erection, and decreased sexual satisfaction. This study aimed to find out the number of LUTS occurence, caused by BPH at Prof. Dr. R. D. Kandou Hospital Manado during period 2009-2013. This was a descriptive retrospective sudy using secondary data from the hospital. The results showed that 8 cases $(15.1 \%)$ in 2009, 16 cases (30.2\%) in 2010, 12 cases (22.6\%) in 2011, 11 cases $(20.8 \%)$ in 2012, and 6 cases $(11.3 \%)$ in 2013. Totally, there were 53 cases during that period of time. The data showed that LUTS caused by BPH most often occured among males aged $\geq 65$ years. Conclusion: In this study, the number of LUTS occurence caused by BPH at Prof. Dr. R. D. Kandou Hospital in 2010 was the highest.
\end{abstract}

Keywords : LUTS, BPH

\begin{abstract}
Abstrak: Lower Urinary Tract Symptoms (LUTS) sering terjadi pada populasi usia lanjut. Salah satu penyebab yang paling sering ialah Benign Prostatic Hyperplasia (BPH). Pria dengan LUTS yang berat akan mengalami penurunan libido, kesulitan mempertahankan ereksi dan penurunan tingkat kepuasan seksual. Penelitian ini bertujuan untuk mengetahui angka kejadian LUTS yang disebabkan oleh BPH di RSUP Prof. Dr. R. D. Kandou Manado periode 2009-2013. Penelitian ini bersifat deskriptif retrospektif dengan menggunakan data sekunder dari RSUP Prof. Dr. R. D. Kandou Manado periode 2009 - 2013. Hasil penelitian menunjukkan angka kejadian BPH pada tahun 20098 kasus (15,1\%), tahun 2010 ditemukan 16 kasus (30,2\%), tahun 2011 ditemukan 12 kasus (22,6\%), tahun 2012 ditemukan 11 kasus (20,8\%) dan tahun 2013 ditemukan 6 kasus (11,3\%), dengan total 53 kasus. Penderita LUTS yang disebabkan oleh BPH tersering muncul pada umur $\geq 65$ tahun. Simpulan: Pada penelitian ini angka kejadian LUTS yang disebabkan oleh BPH di RSUP Prof. Dr. R. D. Kandou Manado periode 2009 - 2013, paling tinggi pada tahun 2010.
\end{abstract}

Kata kunci: LUTS, BPH

Lower Urinary Tract Symptoms (LUTS) merupakan gejala saluran kemih bagian bawah yang biasanya terjadi pada populasi usia lanjut. LUTS dapat memberikan efek negatif untuk kesehatan sehubungan dengan kualitas hidup penderita dan membutuhkan biaya perawatan kesehatan yang tinggi. Banyak faktor yang dapat menyebabkan LUTS pada pria. Salah satu penyebab yang paling sering menyebabkan LUTS pada pria lanjut usia adalah Benign Prostatic Hyperplasia (BPH), yang 
menginduksi Benign Prostatic Enlargement (BPE) dan Benign Prostatic Obstruction (BPO). ${ }^{1}$

BPH merupakan istilah histopatologi yang digunakan untuk menggambarkan adanya pembesaran prostat. BPE merupakan pembesaran prostat jinak yang tidak menyebabkan penyumbatan pada saluran kemih, sedangkan BPO merupakan pembesaran prostat jinak yang dapat menyebabkan penyumbatan pada saluran kemih. BPO ini adalah contoh dari Bladder Outlet Obstruction (BOO). BOO dapat mengganggu aliran urin dan mempunyai peranan penting terjadinya retensi saluran kemih, infeksi saluran kemih, batu kandung kemih, hidronefrosis atau gagal ginjal. BOO juga berhubungan dengan disfungsi kandung kemih termasuk detrusor overactivity, detrusor underactivity dan hipersensitifitas kandung kemih., ${ }^{2,3}$

BPH menjadi masalah global pada pria usia lanjut. Di dunia, hampir 30 juta pria menderita BPH. Pada usia 40 tahun sekitar $40 \%$, usia $60-70$ tahun meningkat menjadi $50 \%$ dan usia lebih dari 70 tahun mencapai 90\%. Diperkirakan sebanyak 60\% pria usia lebih dari 80 tahun memberikan gejala LUTS. Di Amerika Serikat, hampir14 juta pria menderita BPH. Prevalensi dan kejadian BPH di Amerika Serikat terus meningkat pada tahun 1994-2000 dan tahun 1998-2007. Peningkatan jumlah insiden ini akan terus berlangsung sampai beberapa dekade mendatang. ${ }^{4,5}$

Di Indonesia, BPH merupakan penyakit tersering kedua setelah batu saluran kemih. Diperkirakan sekitar 5 juta pria usia diatas 60 tahun menderita LUTS oleh karena BPH. Di RSCM ditemukan 423 kasus BPH pada tahun 1994-1997 dan RS Sumber Waras ditemukan sebanyak 617 kasus pada tahun yang sama.

BPH merupakan masalah serius yang harus diperhatikan karena dapat mempengaruhi kualitas hidup pada pria usia lanjut. Berbagai gejala BPH seperti LUTS dapat menyebabkan disfungsi ereksi dan masalah ejakulasi. Pria dengan LUTS yang berat akan mengalami penurunan libido, kesulitan mempertahankan ereksi dan tingkat kepuasan seksual akan menurun. Survei dari Multi-national Aging Men (MSAM) yang dilakukan di Eropa dan Amerika, menunjukkan bahwa lebih dari 14.000 pria usia $50-80$ tahun mengalami masalah seksual akibat BPH. Data menunjukkan 49\% mengalami kesulitan ereksi, 48\% mengalami gangguan ejakulasi dan $7 \%$ mengalami nyeri saat berhubungan seksual. ${ }^{6,7}$

Masalah BPH ini tetap menjadi masalah kesehatan masyarakat, khususnya pria dengan usia lanjut karena prevalensi yang cukup besar. Meskipun banyak pria yang sering mengabaikan gejala LUTS yang dialami namun perlu untuk mengetahui bagaimana penangan dari BPH ini. Penanganan dari BPH juga menjadi masalah kesehatan masyarakat yang terkait dengan biaya. Data dari Amerika Serikat, pengobatan BPH per tahun sekitar 3,9 miliar dolar. ${ }^{8,9}$

Berdasarkan uraian diatas maka diperlukan data mengenai angka kejadian LUTS yang disebabkan oleh BPH di Kota Manado yang memiliki jumlah penduduk laki-laki usia lanjut sekitar 58.980 jiwa dengan perincian usia 60-64 tahun sebanyak 32.470 jiwa, 65-69 tahun 21.989 jiwa, 70-74 tahun 16.577 jiwa, 75-79 tahun 9.896 jiwa, 80-84 tahun 4.936 jiwa, 85-89 tahun 1.741 jiwa, 90-94 tahun 480 jiwa dan $>95$ tahun 163 jiwa. $^{10}$

\section{METODE PENELITIAN}

Penelitian ini menggunakan bentuk penelitian deskriptif retrospektif dengan menggunakan data sekunder yang diperoleh RSUP Prof. Dr. R. D. Kandou Manado periode 2009 - 2013. Subjek penelitian ialah semua pasien penderita LUTS yang disebabkan oleh BPH yang datang berobat di RSUP Prof. Dr. dr. R. D. Kandou Manado periode tahun 2009-2013.

Kriteria inklusi yaitu semua penderita yang didiagnosis BPH yang dibuktikan dengan pemeriksaan histopatologi dan penderita yang dirawat di RSUP Prof. Dr. dr. R. D. Kandou Manado periode 20092013. Kriteria eksklusi penderita yang tidak didiagnosis BPH. 
Data kasus diperoleh secara retrospektif dari rekam medik penderita di bagian Bedah dan bagian Rekam medik RSUP Prof. Dr. dr. R. D. Kandou Manado periode 2009-2013 kemudian diolah menggunakan Microsof Excel dengan analisa Deskriptif (distribusi).

\section{Lower Urinary Tract Symptoms} (LUTS) merupakan gejala saluran kemih bagian bawah yang biasanya terjadi pada populasi usia lanjut. Salah satu penyebab yang paling sering menyebabkan LUTS pada pria lanjut usia adalah Benign Prostatic Hyperplasia (BPH). BPH merupakan istilah histopatologi yang digunakan untuk menggambarkan adanya pembesaran prostat.

\section{HASIL PENELITIAN}

Jumlah penderita LUTS yang disebabkan oleh BPH sebanyak 53 kasus yang ditemukan di bagian Bedah dan Rekam medik RSUP Prof. Dr. dr. R. D. Kandou Manado selama periode 2009 2013.

Berdasarkan data angka kejadian $\mathrm{BPH}$ di RSUP Prof. Dr. dr. R. D. Kandou Manado, pada tahun 2009 ditemukan 8 kasus (15,1\%), pada tahun 2010 ditemukan 16 kasus (30,2\%), pada tahun 2011 ditemukan 12 kasus (22,6\%), pada tahun 2012 ditemukan 11 kasus (20,8\%) dan pada tahun 2013 ditemukan 6 kasus (11,3\%) (Tabel 1).

Tabel 1. Distribusi LUTS yang disebabkan oleh BPH berdasarkan tahun

\begin{tabular}{lcc}
\hline \hline Tahun & Frekuensi & \% \\
\hline 2009 & 8 & 15,1 \\
2010 & 16 & 30,2 \\
2011 & 12 & 22,6 \\
2012 & 11 & 20,8 \\
2013 & 6 & 11,3 \\
Total & $\mathbf{5 3}$ & $\mathbf{1 0 0 , 0}$ \\
\hline \hline
\end{tabular}

Dari Tabel 2 dapat dilihat kelompok umur 45-64 tahun terdapat 17 penderita (32,1\%) dan kelompok umur lebih dari 65 tahun terdapat 36 penderita (67,9\%).
Tabel 2. Distribusi LUTS yang disebabkan oleh $\mathrm{BPH}$ berdasarkan umur

\begin{tabular}{ccc}
\hline \hline Umur & Frekuensi & \% \\
\hline $45-64$ & 17 & 32,1 \\
$>=65$ & 36 & 67,9 \\
Total & $\mathbf{5 3}$ & $\mathbf{1 0 0 , 0}$ \\
\hline \hline
\end{tabular}

Dari Tabel 3 dapat dilihat distribusi berdasarkan jenis penanganan, yaitu prostatektomi sebanyak 3 kasus (5,7\%) dan TURP sebanyak 50 kasus (94,3\%).

Tabel 3. Distribusi LUTS yang disebabkan oleh BPH berdasarkan penanganan

\begin{tabular}{ccc}
\hline \hline Penanganan & Frekuensi & $\mathbf{\%}$ \\
\hline Prostatektomi & 3 & 5,7 \\
TURP & 50 & 94,3 \\
Total & $\mathbf{5 3}$ & $\mathbf{1 0 0 , 0}$ \\
\hline \hline
\end{tabular}

Dari Tabel 4 dapat dilihat distribusi berdasarkan berat prostat, yaitu berat prostat 10 g sebanyak 6 kasus (11,3\%), berat prostat 15 g sebanyak 4 kasus $(7,5 \%)$, berat prostat $20 \mathrm{~g}$ sebanyak 9 kasus $(17,0 \%)$, berat prostat $25 \mathrm{~g}$ sebanyak 5 kasus (9,4\%), berat prostat $30 \mathrm{~g}$ sebanyak 14 kasus (26,4\%), berat prostat $35 \mathrm{~g}$ sebanyak 3 kasus $(5,7 \%)$, berat prostat $40 \mathrm{~g}$ sebanyak 7 kasus (13,2\%), berat prostat 50 g, 60 g dan 70 g masing-masing sebanyak 1 kasus (1,9\%) dan berat 80 g sebanyak 2 kasus (3,8\%).

Tabel 4. Distribusi BPH berdasarkan berat prostat

\begin{tabular}{ccc}
\hline \hline Berat Prostat & Frekuensi & \% \\
\hline 10 & 6 & 11,3 \\
15 & 4 & 7,5 \\
20 & 9 & 17,0 \\
25 & 5 & 9,4 \\
30 & 14 & 26,4 \\
35 & 3 & 5,7 \\
40 & 7 & 13,2 \\
50 & 1 & 1,9 \\
60 & 1 & 1,9 \\
70 & 1 & 1,9 \\
80 & 2 & 3,8 \\
Total & $\mathbf{5 3}$ & $\mathbf{1 0 0 , 0}$ \\
\hline \hline
\end{tabular}


Berdasarkan Tabel 5 dapat dilihat lama perawatan dari pasien BPH, yaitu 21 hari, 25 hari, 29 hari dan 32 hari masing-masing sebanyak 1 pasien, 8 hari, 19 hari, 20 hari, 35 hari dan 42 hari masing-masing sebanyak 2 pasien (3,8\%), 11 hari, 15 hari, 18 hari dan 24 hari masing-masing sebanyak 3 pasien (5,7\%), 10 hari, 12 hari, 13 hari dan 14 hari masing-masing sebanyak 4 pasien (7,5\%) dan 17 hari sebnyak 5 pasien $(9,4 \%)$.

Tabel 5. Lama perawatan pasien LUTS yang disebabkan oleh BPH

\begin{tabular}{ccc}
\hline \hline Lama perawatan & Frekuensi & $\mathbf{\%}$ \\
\hline 8 & 2 & 3,8 \\
9 & 2 & 3,8 \\
10 & 4 & 7,5 \\
11 & 3 & 5,7 \\
12 & 4 & 7,5 \\
13 & 4 & 7,5 \\
14 & 4 & 7,5 \\
15 & 3 & 5,7 \\
17 & 5 & 9,4 \\
18 & 3 & 5,7 \\
19 & 2 & 3,8 \\
20 & 2 & 3,8 \\
21 & 1 & 1,9 \\
22 & 2 & 3,8 \\
23 & 2 & 3,8 \\
24 & 3 & 5,7 \\
25 & 1 & 1,9 \\
29 & 1 & 1,9 \\
32 & 1 & 1,9 \\
35 & 2 & 3,8 \\
42 & 2 & 3,8 \\
Total & $\mathbf{5 3}$ & $\mathbf{1 0 0 , 0}$ \\
\hline \hline
\end{tabular}

\section{BAHASAN}

Dari hasil penelitian memperlihatkan jumlah kasus yang ditemukan di RSUP Prof. Dr. dr. R. D. Kandou Manado dalam kurun waktu 5 tahun, yaitu dari tahun 2009 - 2013 sebanyak 53 kasus, dengan kriteria inklusi bahwa 53 kasus yang didapat di bagian Bedah dan bagian Rekam Medik ialah kasus yang catatan mediknya disimpan atau ditemukan.

Tabel 1 menunjukkan bahwa distribusi penderita LUTS yang disebabkan oleh BPH periode 2009 - 2013, terbanyak pada tahun 2010 yaitu sebanyak 16 kasus (30,2\%), lalu disusul tahun 2011 yaitu sebanyak 12 kasus (22,6\%), kemudian tahun 20098 kasus (15,1\%) dan yang terakhir tahun 2013 sebanyak 6 kasus (11,3\%).

Berdasarkan data di Bagian Bedah dan Rekam Medik, tahun 2010 merupakan tahun terbanyak angka kejadian BPH. Pada tabel 2, didapatkan bahwa kelompok umur tersering yang menderita LUTS yang disebabkan oleh BPH adalah kelompok umur $>=65$ tahun sebanyak 36 kasus (67,9\%) kemudian kelompok umur 45-64 tahun sebanyak 17 kasus (32,1\%). Kelompok umur $>=65$ tahun yaitu kelompok tertinggi pada penyakit $\mathrm{BPH}$, ini dikarenakan pada umur tersebut merupakan resiko terjadinya $\mathrm{BPH}$ karena mulai mengalami ketidakseimbangan hormon.

Pada tabel 3 didapatkan bahwa penanganan pasien LUTS yang disebabkan oleh BPH yang terbanyak adalah TURP dengan 50 kasus $(94,3 \%)$ dan prostatektomi sebanyak 3 kasus (5,7\%). Penangan dengan TURP lebih sering digunakan karena tindakan ini tidak memerlukan insisi pada kulit, lama perawatan menjadi lebih singkat dan mengurangi perdarahan.Penanganan ini juga memberikan hasil yang tidak banyak berbeda dengan tindakan operasi terbuka.Penangan dengan prostatektomi dianjurkan untuk ukuran prostat yang sangat besar (>100 gram).

Pada tabel 4, didapatkan bahwa berat prostat yang sering didapatkan saat pembedahan adalah 30 gram dengan 14 kasus (26,4\%), kemudian 20 gram sebanyak 9 kasus (17,0\%), 10 gram sebanyak 6 kasus (11,3\%), 25 gram sebanyak 5 kasus (9,4\%), 15 gram sebanyak 4 kasus (7,5\%), 35 gram sebanyak 3 kasus (5,7\%), 80 gram sebanyak 2 kasus (3,8\%) dan yang terakhir 50, 60 dan 70 gram masing-masing 1 kasus (1,9\%).

Pada tabel 5, didapatkan lama perawatan dari pasien LUTS yang disebabkan oleh BPH, yaitu 17 hari sebanyak 5 pasien $(9,4 \%)$, kemudian 10 
hari, 12 hari, 13 hari dan 14 hari masingmasing sebanyak 4 pasien (7,5\%), 11 hari, 15 hari , 18 hari dan 24 hari masing-masing sebanyak 3 pasien (5,7\%), 8 hari, 9 hari, 19 hari, 22 hari, 23 hari, 35 hari dan 42 hari masing-masing sebanyak 2 pasien (3,8\%) dan yang terakhir 21 hari, 25 hari, 29 hari dan 32 hari masing-masing sebanyak 1 pasien (1,9\%).

\section{SIMPULAN}

Angka kejadian LUTS yang disebabkan oleh BPH di RSUP Prof. Dr. dr. R. D. Kandou Manado periode 2009 - 2013 paling tinggi pada tahun 2010.

Penderita LUTS yang disebabkan oleh BPH tersering muncul pada umur $\geq 65$ tahun. Penanganan yang sering diberikan pada pasien LUTS yang disebabkan oleh $\mathrm{BPH}$ ialah pembedahan endourologi TURP karena penanganan ini merupakan baku emas penganan $\mathrm{BPH}$. Penganan ini juga mengurangi lama perawatan pasien, mengurangi perdarahan dan tidak memerlukan insisi pada kulit. Berat prostat dari pasien $\mathrm{BPH}$ yang didapat pada penelitian ini tersering 30 gram. Lama perawatan pasien LUTS yang disebabkan oleh BPH adalah 4-5 hari pada pasien tanpa komplikasi dan rata-rata 10-17 pada pasien dengan komplikasi.

\section{DAFTAR PUSTAKA}

1. Abrams P, Kelleher CJ, Kerr LA, et al. Overactive bladder significantly affect quality of life. Am J Manag 2000;6 (Suppl 11):580-90.
2. Coyne KS, Sexton CC, Irwin DE, et al. The impact of overactive bladder, incontinence and other lower urinary tract symptoms on quality of life, work productivity, sexuality and emotional well-being in men and women. BJU International: 2008.

3. Irwin DE, Mungapen L, Milsom I, et al. The economic impact of overactive bladder syndrome in six Western countries. BJU International: 2009.

4. Parsons KJ. Benign Prostatic Hyperplasia and Male Lower Urinary Tract Symptoms: Epidemiology and Risk Factor. PMC: 2010.

5. Girman CJ. Population-based Studies of Epidemiology of Benign Prostate Hyperplasia. Br J Urol 1998;82 (Supll).

6. Wei JT, Calhoun E, Jacobsen SJ. Urologic diseases in America project: benign prostatic hyperplasia. J Urol. 2005; 173 (4).

7. Verhame KM, Dieleman JP, Bleumink GS, et al. Incidence and prevalence of lower urinary tract symptoms suggestive of benign protatic hyperplasia in primary care. Eur Urol 2002;42 (4).

8. Hu TW, Wagner TH, Bentkover JD, et al. Estimated economic costs of overactive bladder in the United States. Urology. 2003; 61 (6).

9. Saigal CS, Joyce G. Economic costs of benign prostatic hyperplasia in the private sector. J Urol. 2005; 173 (4).

10. Badan Pusat Statistk. Manado Dalam Angka 2013. 